\title{
ENTRE OLHARES E (IN)VISIBILIDADES: REFLEXÕES SOBRE FOTOGRAFIA COMO PRODUÇÃO DIALÓGICA http://dx.doi.org/10.1590/1984-0292/895
}

\author{
Laura Kemp de Mattos ${ }^{\star}$, Andréa Vieira Zanella, Adriano Henrique Nuernberg \\ Universidade Federal de Santa Catarina, Florianópolis, SC, Brasil
}

\section{ReSUMO}

A proposta deste artigo é tensionar, em fotografias produzidas por crianças com deficiência visual, o que se vê e o que se deixa de ver, as visibilidades e invisibilidades objetivadas nas fotos. Sendo as fotografias concebidas como produção discursiva e dialógica, a leitura das mesmas possibilita problematizar a relação que elas estabelecem com a realidade em que vivem. Como procedimentos metodológicos foram eleitos a produção de fotografias e o desenvolvimento de uma oficina estética. Para a análise estabelecemos uma confrontação das fotos no plano da significação, com base na análise dialógica do discurso, a partir da concepção do Círculo de Bakhtin (2010a). Os sentidos enfocados trazem à luz a realidade das crianças, independentemente de serem crianças com deficiência visual. Este aspecto foi muito significativo: os modos de (vi)ver o mundo expressos nas imagens são antes de tudo olhares de meninas e meninos.

Palavras-chave: deficiência visual; fotografia; linguagem; imaginação.

\section{BETWEEN LOOKS AND (IN)VISIBILITIES:}

\section{REFLECTIONS ABOUT PHOTOGRAPHY AS A DIALOGIC PRODUCTION}

\section{Abstract}

The proposal of this article is to tension, in photographs taken by blind children, what is seen and not seen, the visibilities and invisibilities objectified in the photos. Being that the photos conceived as discursive and dialogical production, its reading enables to problematize the relation these children establish with the reality which they live in. As methodological procedures, were elected the photo production and the development of an aesthetic workshop. For the analysis it was established a confrontation of photos on the meaning level, taking the dialogical analysis of speech, from the perception of Bakhtin Circle (2010a). The senses focused bring light to the reality of the children, despite being eye shortage children. This regard was very meaningful: the ways to seellive the world expressed in the images are before anything sights of children.

Keywords: disabled eyesight; photography; language; imagination.

\footnotetext{
^Endereço para correspondência: Universidade Federal de Santa Catarina, Centro de Filosofia e Ciências Humanas, Departamento de Psicologia. Campus Universitário- Trindade - sala CFH 212. Trindade. 88010970 - Florianópolis, SC - Brasil.

E-mail:kemp.laura@gmail.com, azanella@cfh.ufsc.br, adrianoh@cfh.ufsc.br
} 


\section{INTRODUÇão}

Toda fotografia é marcada pelo olhar de quem a produziu e a sua leitura traz as marcas dos olhares de quem a admira, ambos olhares socialmente constituídos. Partindo desta compreensão, a proposta deste estudo é tensionar, em fotografias produzidas por crianças com deficiência visual, o que se vê e o que se deixa de ver, as visibilidades e invisibilidades objetivadas nas fotos. Sendo as fotografias concebidas como produção discursiva e dialógica, a leitura das mesmas possibilita problematizar a relação que elas estabelecem com a realidade em que vivem.

Na nossa sociedade marcada por paradigmas visuocêntricos, constituem-se modos de (vi)ver o mundo extremamente pautados por uma lógica da visão, da reprodução de imagens. De acordo com Peixoto (1990, p. 361), a questão do olhar está no centro do debate da cultura e das sociedades contemporâneas, pois um "mundo onde tudo é produzido para ser visto, onde tudo se mostra ao olhar, coloca necessariamente o ver como um problema". E aqueles que não veem? Como constituem modos de ver e viver a realidade? Estas inquietações nos levaram a tecer um diálogo com diferentes autores e contextos, visando compor fragmentos e propor reflexões para ampliar o conhecimento sobre o tema.

Para o enfoque histórico-cultural em psicologia, embasamento deste estudo, nas relações interpessoais produzem-se significações sobre o vivido que são singularmente apropriadas, promovendo a constituição do psiquismo. Assim, as significações coletivamente produzidas nas relações entre as pessoas e a realidade são apropriadas e viabilizam que se constituam olhares, modos singulares de (vi)ver o mundo. São olhares, portanto, que não dependem apenas da visão; pois envolvem os cinco sentidos, as emoções, a linguagem, o pensamento, a atividade reflexiva e as relações estabelecidas com outras pessoas (ZANELLA, 2006).

As relações interpessoais, por sua vez, são mediadas pela polissemia das vozes sociais que constituem a cultura (BAKHTIN, 2010a, 2010b) e que se objetivam de variadas formas nos espaços e suas condições arquitetônicas, no modo como se organiza a vida em sociedade, nas imagens e nos objetos que elegemos como depositários de afetos.

Essas questões constituem a pauta das discussões que serão apresentadas neste texto.

\section{SOBRE A PESQUISA}

Este artigo é uma parte da dissertação de mestrado "Sobre Fotografia e (In) Visibilidades: olhares de crianças com deficiência visual" apresentada ao Programa de Pós-Graduação em Psicologia da Universidade Federal de Santa Catarina (KEMP, 2011). O objetivo da pesquisa foi problematizar, a partir de imagens fotográficas produzidas por crianças com deficiência visual, seus olhares sobre o contexto em que vivem. 
A pesquisa realizada pautou-se em uma perspectiva ética de viver o pesquisar como um acontecimento, processo em constante movimento, interligado a outros acontecimentos, conhecimentos e valores sociais. Pesquisar é assim um ato de compor fragmentos, (re)criar experiências e transformar realidades (FONSECA et al., 2006). No encontro com os sujeitos com os quais se pesquisa, criam-se espaços de enunciação que possibilitam o pesquisarCOM, no qual pesquisador e sujeitos produzem uma forma dialógica de conhecimento (FREITAS, 1997; JOBIM E SOUZA; CASTRO, 2008; MORAES; KASTRUP, 2010).

Produção dialógica de conhecimento implica (re)criação de sentidos e o pesquisar acontecimento pode também ser compreendido como intervenção (COSTA; COIMBRA, 2008), pois contribui para a ressignificação dos modos de (vi)ver o mundo.

Como procedimentos metodológicos foram eleitos a produção de fotografias e o desenvolvimento de uma oficina estética ${ }^{1}$ com o grupo de crianças com quem pesquisamos.

A oficina estética "Experiências de (re)criação do olhar" foi realizada em cinco encontros com 11 crianças com idades entre quatro a 12 anos de idade; sendo seis cegas congênitas, duas sem deficiência visual e três com baixa visão.

$\mathrm{Na}$ oficina foram proporcionadas vivências estéticas utilizando diferentes linguagens artísticas como ferramentas para a sensibilização do olhar, possibilitando reflexões sobre os modos de (vi)ver o mundo e produção de sentidos outros da/na realidade.

Como meio de divulgação dos resultados da oficina estética foi realizado um documentário por uma equipe do curso de cinema que propôs abordar a infância e processos de criação, por meio do registro audiovisual dos encontros e de entrevistas com as crianças, familiares e educadores (OLHOS..., 2010).

Em função da gravação do documentário, desenvolvemos atividades com objetivo de apresentar os equipamentos e as pessoas que compunham a equipe.

A experiência de participar da oficina e da gravação do filme foi significativa para as crianças com quem pesquisamos e para todos os envolvidos. Em muitos momentos, membros da equipe tornaram-se educadores, auxiliaram e brincaram com as crianças.

Desenvolvemos também atividades utilizando a fotografia, seja como tema, seja como ferramenta. Para além dos encontros da oficina, as crianças foram convidadas a produzir imagens fotográficas dos aspectos significativos nos/dos espaços que as constituem. Para tanto, foram disponibilizadas câmeras fotográficas de uso único com 27 poses. Naquele momento, primeiro dia da oficina estética, elas foram orientadas sobre o funcionamento do equipamento e solicitamos que objetivassem em fotografias experiências significativas e aspectos importantes de seu cotidiano. Explicamos que as fotos poderiam ser produzidas com o auxílio de outras pessoas, contudo, o olhar do fotógrafo deveria ser o olhar da criança; ela 
deveria ser a autora e diretora das fotografias. Então elas levaram as câmeras para casa e devolveram após uma semana, com os 27 "clicks" livremente criados em suas relações com o contexto em que vivem.

Para este artigo selecionamos fotos produzidas por cinco crianças para análise. Utilizamos seus nomes completos, garantindo a autoria e identidade, pois expô-los não irá submetê-las a nenhum risco (KRAMER, 2002): ao contrário, é um modo de lhes dar visibilidade como artistas e autoras. São elas: Jonathan da Silva Martins, sete anos de idade, cego; Pamela Maiara Castro, 11 anos de idade, cega; Ana Carolina Ferreira, sete anos de idade, com baixa visão; Vinícius Luiz Maciel, oito anos de idade, com baixa visão; Naiara Ramilo da Silva, 10 anos de idade, com baixa visão. ${ }^{2}$

No que tange à utilização da fotografia como ferramenta de pesquisa, nas últimas décadas, observa-se um aumento significativo de sua utilização no Brasil (DE TACCA, 1991; ACHUTTI, 2004; TITTONI, 2009; SCHWEDE, 2010; ZANELLA, 2011; ASSIS, 2011; MUND, 2012). No âmbito da psicologia é considerada uma "forma alternativa de linguagem em pesquisa" (MAURENTE; TITTONI, 2007, p. 34) e o principal objetivo de seu uso é a atribuição de significado à imagem.

Encontram-se registros de métodos que utilizam a fotografia desde os primórdios da pesquisa científica em psicologia no século XIX, período no qual também tem origem o desenvolvimento do processo fotográfico (NEIVA-SILVA; KOLLER, 2002; JUSTO; VASCONCELOS, 2009). Atualmente, de acordo com Neiva-Silva e Koller (2002), podem-se identificar 4 funções principais da fotografia nas pesquisas em psicologia: (1) registro de informações; (2) modelo - o conteúdo/tema da foto é usado como disparador da fala dos sujeitos; (3) feedba$c k$ - são apresentados ao sujeito registros imagéticos de um processo anterior de avaliação; (4) autofotográfica - "cada participante recebe uma câmera fotográfica [...]. Posteriormente, é solicitado [à criança] a tirar determinado número de fotos na tentativa de responder a uma questão específica. Após a revelação do filme, é analisado o conteúdo das fotos" (NEIVA-SILVA; KOLLER, 2002, p. 238).

Neste estudo compreendemos a fotografia como produção discursiva e analisamos os sentidos impressos nas fotos, entendendo-os como vestígios dos modos de (vi)ver das crianças. Portanto, na metodologia adotada neste estudo ela assume a função autobiográfica. Com base nessa perspectiva, para a análise estabelecemos uma confrontação das imagens no plano da significação, analisando os discursos objetivados nas fotos com base na análise dialógica do discurso, a partir da concepção do Círculo de Bakhtin (2010a).

Cumpre destacar que fotografar é um processo de criação e (trans)formação da realidade, pois, de modo simultâneo e inseparável, o sujeito seleciona e (re) elabora recortes da realidade (KOSSOY, 2007), convertendo-os em produtos de sua imaginação e os objetiva na imagem fotográfica. A objetivação é uma (re) elaboração criativa de experiências vivenciadas, pois o fotógrafo pode (re)criar e objetivar fragmentos de sentidos de acordo com seus olhares, interesses, emoções, projetos etc., produzidos constante e incessantemente em sua experiência singular. 
A fotografia, nesse sentido, é um recorte do contexto, um click que é atravessado, marcado e direcionado pelo olhar de seu criador. Com isso, traz indícios dos modos de (vi)ver o mundo do fotógrafo (ACHUTTI, 2004; SONTAG, 2004; TITTONI, 2009). É, portanto, uma produção de um único instante no decorrer do tempo, produção de uma subjetividade a partir da condição espaço-temporal e deve ser lida a partir do contexto histórico e cultural de sua produção (KOSSOY, 2007). Vigotski (2001) destaca que a palavra deve ser compreendida na frase, a frase no texto e o texto no contexto; assim, também podemos pensar a imagem fotográfica apreendida a partir dos contextos de sua produção e leitura.

A partir das relações dialógicas estabelecidas com outros, as imagens-fragmentos do contexto tornam-se significativas para os sujeitos. No campo intersubjetivo mediado pela palavra de muitos outros, sentidos visuais são (re) significados e tornados próprios, sentidos estes que são experienciados com todo o corpo. Esclarece Bakhtin (2010a, p. 38) que todos os signos não-verbais "banham-se no discurso e não podem ser totalmente isolados nem totalmente separados dele [...]. A palavra está presente em todos os atos de compreensão e em todos os atos de interpretação". Afirma-se assim a inexorável relação entre fotografia e discurso, entre imagem e palavra.

Com relação especificamente à linguagem e à deficiência visual, para Vygotski $^{3}$ "a palavra vence a cegueira" (VIGOTSKI, 1997, p. 108). De acordo com o autor, a mediação do signo verbal é uma possibilidade social que favorece a superação dos limites impostos pela restrição da experiência visual, viabilizando a inserção no universo simbólico. Corroborando esta perspectiva, Evgen Bavčar (2000, p. 9), filósofo e fotógrafo cego, afirma que "logo que nós não dispomos mais de imagens, é o verbo quem nos fornece novas possibilidades". Também Joana Belarmino de Sousa (2009, p. 184), jornalista cega desde o nascimento, afirma que é por meio da palavra, mais especificamente da literatura, que ela vê "corporificado em texto o pôr-do-sol, o céu estrelado, a beleza de um arco-íris". Nesse sentido, para os cegos é pela palavra que as imagens são (re)conhecidas e compartilhadas.

Cumpre sublinhar que o que difere a organização do sistema psicológico de pessoas com deficiência são somente as mediações e os nexos estabelecidos entre os processos psicológicos (VIGOTSKI, 1997). No que tange à cegueira, relações estabelecidas entre linguagem, pensamento, imaginação e percepção viabilizam a (re)organização do psiquismo (NUERNBERG, 2008).

Em consonância com a afirmação de Oliver Sacks no documentário Janela da Alma (JANELA..., 2001), para os cegos a imaginação é olho do pensamento, um olhar cujo substrato não se pauta no registro mnemônico das sensações visuais, mas nas significações produzidas a partir dos sentidos remanescentes transformados socialmente na/pela cultura. Com isso, a imaginação tem um papel diferenciado, pois possibilita às pessoas com deficiência visual "ver" e criar uma imagem com base em outras informações sensoriais, mediadas principalmente pela linguagem, na sua capacidade de conferir à realidade uma existência simbólica.

Ao criarem fotografias a partir de imagens constituídas com os demais sentidos, os cegos (re)inventam modos de (vi)ver e apresentar o mundo. 
Nesse âmbito, concordamos com Oliver Sacks (2010, p. 210) e também nos questionamos:

se de fato existe uma diferença fundamental entre a vivência e a descrição, entre o conhecimento direto e o conhecimento mediado do mundo, por que então a linguagem é tão poderosa? A linguagem, a mais humana das invenções, pode possibilitar o que, em princípio, não deveria ser possível. Pode permitir a todos nós, inclusive os cegos congênitos, ver com os olhos de outras pessoas.

A palavra, portanto, é compreendida como um meio ativo e mutável de comunicação dialógica. "Ela nunca basta a uma consciência, a uma voz. Sua vida está na passagem de boca em boca, de um contexto para outro, de um grupo social para outro, de uma geração para outra" (BAKHTIN, 2010b, p. 232). Assim compreendemos também a fotografia como produção discursiva e dialógica, na medida em que sua existência está na perpétua comunicação com os outros, no entrecruzamento de olhares que, mediados pela linguagem, viabilizam sua existência e possibilitam a constituição de sentidos outros.

As fotografias, por conseguinte, expressam olhares; trazem imagens de objetos, pessoas e contextos significativos que se convertem em signo, "o qual, sem deixar de fazer parte da realidade material, passa a refletir e a refratar, numa certa medida, uma outra realidade" (BAKHTIN, 2010a, p. 31), sendo o refratar possibilidade de construção de novos mundos. A intervenção fotográfica, pois, é inventiva, multiplica o contexto, concebida neste trabalho como in(ter)venção (AXT; KREUTZ, 2003).

Deste modo, são diversas as refrações possíveis na leitura das fotos. Isto porque os sentidos são constituídos historicamente e abalizados pela diversidade de experiências humanas, com suas tensões e contradições.

Além disso, como os processos semióticos só refletem o mundo refratando-o, os signos são espaços de encontro e confronto de diferentes índices sociais de valor, plurivalência que lhes dá vida e movimento. [...] o signo é necessariamente pluriacentuado e plurívoco; ele pode ser sempre outro (FARACO, 2009, p. 54).

Nesse âmbito, cada pessoa faz sua leitura dos sentidos expressos nas fotos de acordo com sua experiência singular, socialmente constituída em um vasto campo de possibilidades.

Na seleção e análise que fizemos das imagens buscamos descrevê-las e discuti-las a partir do que dão a ver aos olhos dos pesquisadores. Valorizando o potencial narrativo da imagem fotográfica, procuramos ler textos visuais como forma de escritura (ACHUTTI, 2004). Expressamos nosso olhar sobre os senti- 
dos ali objetivados e dialogamos com os autores que fundamentam esse estudo, cientes de que nenhuma descrição "é capaz de contemplar as preferências de todos os espectadores" (DAVID; HAUTEQUESTT; KASTRUP, 2012, p. 129).

Cumpre esclarecer que, assim como Müller (2013), não realizamos nesta pesquisa entrevistas com as crianças sobre as fotos, pois consideramos que as imagens falam: são expressão do olhar delas, das escolhas que fizeram e do que puderam fotografar. São, portanto, produções discursivas, com as quais cabe ao pesquisador dialogar (CORD; FERREIRA, 2006).

Importante enfatizar, pois, que neste artigo analisamos exclusivamente as fotos produzidas pelas crianças. Buscamos, deste modo, olhar para as fotografias, estabelecer com elas relações dialógicas e, nos sentidos ali expressos, conjecturar possibilidades de leitura.

Optamos por fazer uma descrição detalhada dos aspectos visuais das imagens apresentadas neste trabalho para possibilitar a apropriação dessas informações por pessoas cegas. Estas descrições estão disponíveis em notas de fim que acompanham cada uma das fotografias.

\section{In(ter)venção Fotográfica: Resultados e Discussão}

Com as fotos produzidas pelas crianças problematizamos neste artigo seus olhares e modos de (vi)ver o mundo, a partir das suas escolhas no foco da câmera fotográfica, do que elas trouxeram como temáticas de investigação.

No conjunto de imagens há alguns aspectos comuns. O primeiro ponto de similaridade diz respeito à vida privada: foram produzidas muitas fotos de familiares em cenas cotidianas, na sala, na cozinha, sendo que nem sempre posavam ou pareciam estar contentes em serem fotografados. Algumas fotos registraram momentos e olhares espontâneos, em ângulos de visão diferentes dos comumente registrados em álbuns de família. ${ }^{4}$

Fotografar a família expressa sentidos e emoções das crianças que as levaram a produzir estas imagens, sentidos estes relacionados aos vínculos que ali se inscrevem e se fortalecem no dia a dia. Assim, elas deram visibilidade a aspectos afetivos de suas vivências sociais. Destaca-se a dimensão emocional presente não somente nestas, mas na maior parte das produções.

Cumpre salientar que a maioria das fotos foi criada no interior das residências. Essa característica do conjunto de imagens, embora possa ser justificada em virtude da condição da deficiência visual, objetiva também uma tendência do mundo atual e da vida privada não só de crianças cegas, mas de toda a sociedade: privatização da vida social.

$\mathrm{Na}$ cidade atual, as ruas, esquinas e praças, possibilidades de encontros de outrora, são constantemente vivenciadas apenas como passagens. Aqueles que transitam, pouco interagem socialmente. O viver está cada vez mais individualizado, assim como os espaços públicos mais privatizados. As pessoas vivem apressadas o cotidiano da cidade; transitam pelas ruas indo e vindo, em perma- 
nente movimento (ZANELLA, 2009). Os modos de vida que organizam a cidade, portanto, constituem as subjetividades e olhares daqueles que a habitam, observado nas fotografias produzidas.

Outro aspecto presente nas produções de quatro das cinco crianças com quem pesquisamos foram os autorretratos (Figura1). ${ }^{5}$

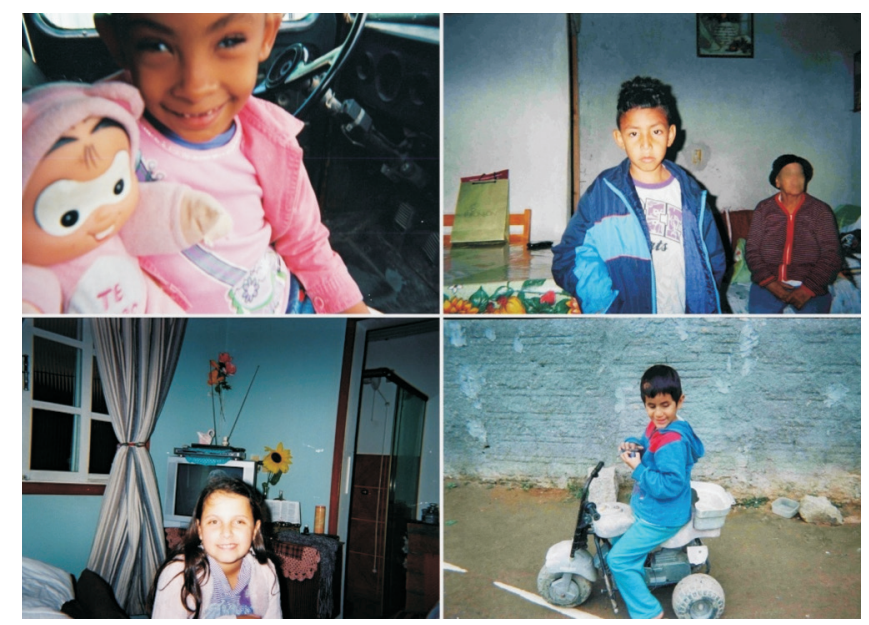

Figura 1 - Autorretratos

Solicitadas a fotografarem o que lhes era significativo no contexto em que vivem, as crianças escolheram se posicionar em frente à câmera. Nessas imagens elas foram ao mesmo tempo modelos e diretoras do olhar do fotógrafo, alguém por elas eleito para o registro imagético. Não é possível dizer quem produziu as fotos, provavelmente pessoas que lhes são próximas. Mas é possível pressupor que elas tenham colaborado ativamente na composição da imagem, via escolha dos cenários e os modos como se apresentaram para o click. Se esse pressuposto é aceito, as crianças podem ser consideradas coautoras ou diretoras da imagem, além de protagonistas.

Nas imagens que compõem a Figura 1, elas produziram fotografias de si em que se apresentam para o outro. Evidencia-se, assim, a importância do olhar do outro como constitutivo do olhar de si. Para Bakhtin, "pode-se dizer que o homem tem uma necessidade estética absoluta do outro, do seu ativismo que vê, lembra-se, reúne e unifica, que é o único capaz de criar para ele uma personalidade externamente acabada; tal personalidade não existe se o outro não a cria" (BAKHTIN, 2003, p. 33). Desse modo, tanto o ver como o não ver são socialmente constituídos: todas as pessoas constituem olhares, modos de (vi)ver o mundo, a partir da experiência acumulada, vivida com todo o corpo e pelos olhos de muitos outros.

Os signos não-verbais, dentre eles as fotografias, inserem-se num determinado contexto dialógico. Entender o pesquisarCOM como acontecimento possibilita que seja criado um campo de enunciação entre sujeitos, pesquisador e contexto. Deste modo, cada enunciado é compreendido como uma unidade da comunicação 
discursiva (BAKHTIN, 2010a). Um enunciado, portanto, pode se realizar não só em palavras, mas também em imagens fotográficas e sua entonação não é necessariamente verbal: podemos percebê-la nos sentidos objetivados nas fotos.

Destacam-se nas fotografias (Figura 1) em diferentes entonações os enunciados das crianças a partir de outro lugar, não como crianças com deficiência visual, mas autorretratos de um lugar da infância, como crianças e nada mais. Nessas imagens delineiam-se contextos significativos de quem as produziu; nelas os protagonistas aparecem com brinquedos ou em ambientes domésticos. Esses contextos nos remetem a conhecidos espaços de conforto e afeto, espaços do brincar e do compartilhar em família.

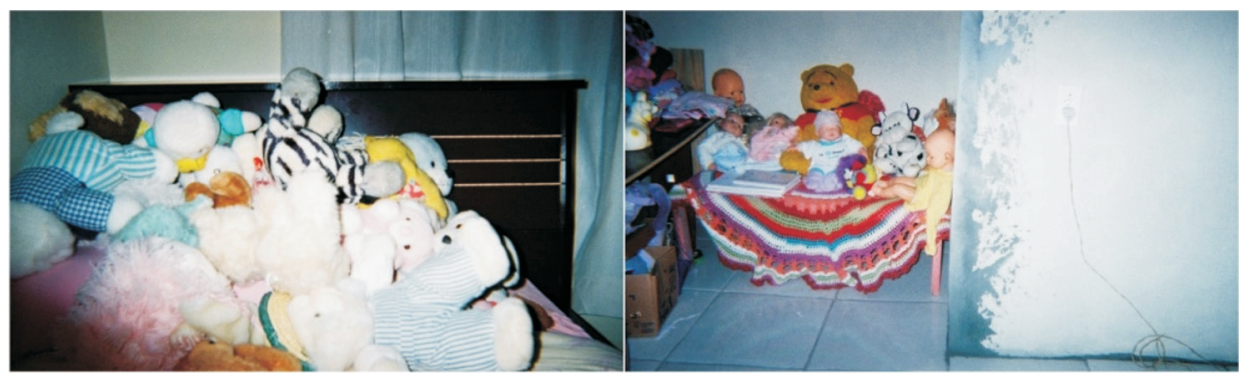

Figura 2 - Brinquedos fotografados por Pâmela e Naiara.

Contextos da infância também são fotografados por Pâmela e Naiara (Figura 2). ${ }^{6}$ As duas meninas fotografaram um mesmo objeto: bichos de pelúcia e bonecas, brinquedos significativos do universo em que vivem e que também trazem à luz possibilidades afetivas.

Cumpre enfatizar que o brincar é uma atividade cultural e essencial ao desenvolvimento humano (VIGOTSKI, 2009). O brincar faz-se indispensável à constituição dos sujeitos, é um dos modos de apropriação do mundo simbólico; é resultado de um processo de inserção da criança na cultura que a possibilita dessa se apropriar e ao mesmo tempo reinventá-la. De acordo com Benjamin (2002) e Brougère (1995; 1998), o brincar e os brinquedos são produtos de uma determinada sociedade, revelam aspectos culturais e expressam modos de ver o mundo socialmente compartilhados.

As brincadeiras do universo feminino diferenciam-se do masculino. Para Brougère (1995), prevalecem nas escolhas das meninas temáticas de brincadeiras relacionadas aos cuidados da casa e da família. Brincar de casinha, de interpretar o papel de mãe nos cuidados com bebês são jogos de faz-de-conta compartilhados em culturas lúdicas que são (re)criados a partir dos valores e papéis sociais da cultura mais ampla em que se inscrevem. As fotografias de Naiara e Pâmela, de suas bonecas e bichinhos de pelúcia, expressam esse aspecto cultural do brincar feminino e contrastam com a Figura 1, que apresenta Jonathan em um triciclo motorizado, trazendo um elemento do universo masculino. 
As imagens criadas por Ana Carolina também expressam aspectos emocionais. Na Figura $3^{7}$ ela enquadra de cima para baixo um cachorro, posicionado bem ao centro, equilibrado nas duas patas traseiras, pulando em sua direção e olhando para a câmera. Em um click ela congela seu movimento.

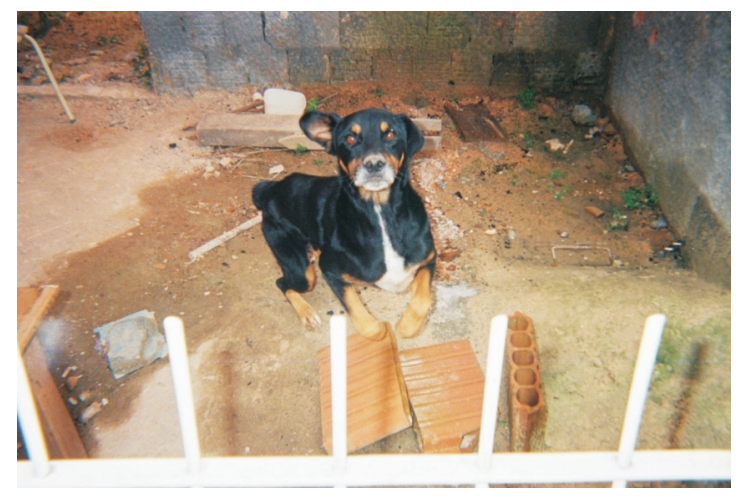

Figura 3 - Cachorro fotografado por Ana Carolina.

Analisando o filme é possível observar a sequencia de movimentos de Ana Carolina. Primeiro ela fotografou o cachorro (Figura 3) e em seguida um pássaro (Figura 4). ${ }^{8}$ Ela criou, com isso, uma cadeia semiótica, mostrando a relação de um signo com outro e que lhes são significativos; criando objetivações de vivências particulares, expressou redes de significação que a constituem enquanto criança.

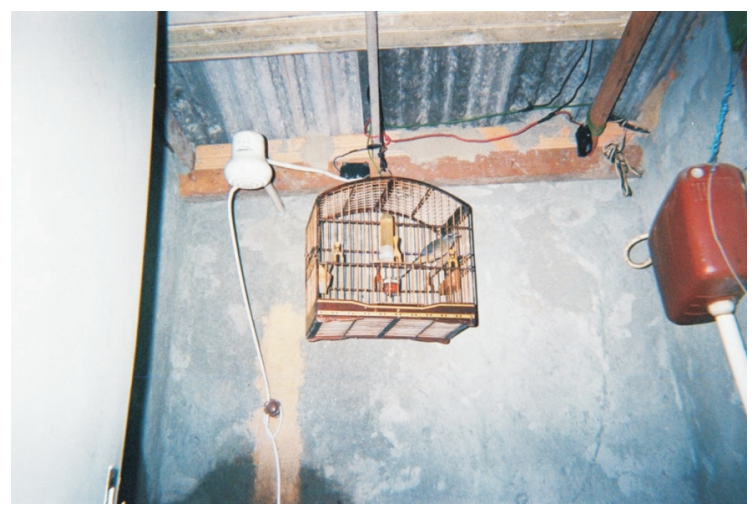

Figura 4 - Pássaro fotografado por Ana Carolina.

Não podemos afirmar que esses são seus animais de estimação, pois não conversamos com as crianças sobre suas produções e não sabemos quais foram os objetivos de Ana Carolina com as fotos, mas analisando o que dizem as imagens, podemos observar os sentidos e cadeias semióticas que se estabeleceram.

As crianças, quando receberam as câmeras fotográficas, foram orientadas sobre as possibilidades de produzirem imagens de aspectos táteis, auditivos, gustativos ou olfativos, pois não só o que é visual pode constituir uma imagem mas 
também outros elementos aparentemente invisíveis. Por exemplo, numa de suas fotografias, Evgen Bavčar fotografou o som do sino que sua sobrinha utilizava ao correr e dançar (BAVČAR, 2010): para ele, trata-se do registro do invisível.

Destacamos que também sentidos invisíveis podem ser lidos em algumas fotos das crianças, como na foto do cantar do pássaro (Figura 4) ou do barulho do cão (Figura 3), nas quais Ana Carolina pode ter registrado imagens de sons.

Também uma fotografia de elementos sonoros foi produzida por Jonathan: a imagem de uma televisão e de uma caixa de som (Figura 5), ${ }^{9}$ registro de bens de consumo que para ele possivelmente são importantes.

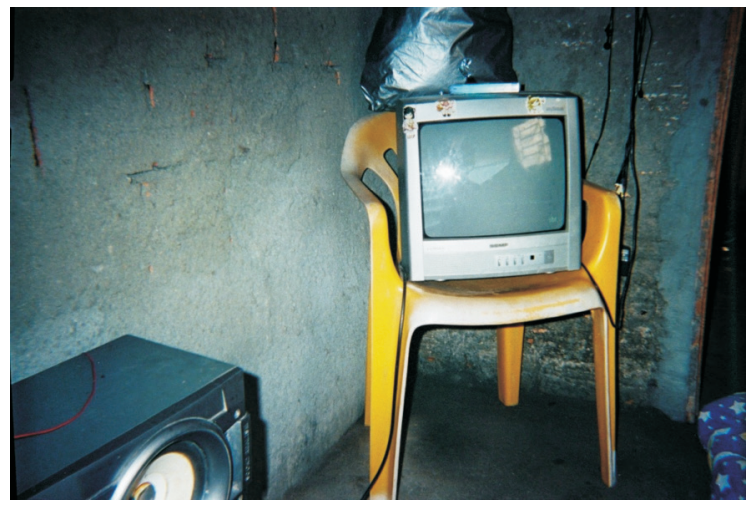

Figura 5 - Televisão e caixa de som fotografados por Jonathan.

Faz-se necessário esclarecer que, para as pessoas privadas da visão, o psiquismo se (re)organiza para possibilitar relacionar-se com a realidade. Conforme Sacks $(2007 ; 2010)$, a plasticidade e a flexibilidade do cérebro humano viabilizam que o córtex visual seja realocado para os demais sentidos, possibilitando relações outras entre os processos psicológicos superiores.

Bavčar (2010) afirma que, do mesmo modo que vemos imagens visuais a partir da reflexão da luz, os cegos ouvem o nascer do dia com o canto dos pássaros e distinguem a "voz" da manhã e a da noite. Assim, ao criarem imagens dos aspectos visuais de sua experiência pautadas por outros canais perceptivos, as pessoas com deficiência visual podem "ver" com a imaginação, "o olho do pensamento" (SACKS, 2007).

Importante enfatizar que tanto o ver como o não ver são socialmente constituídos, na medida em que "o mundo não nos é dado: construímos nosso mundo através da experiência, classificação, memória e reconhecimento incessantes" (SACKS, 1995, p. 129). Assim, independentemente da visão, constituímos modos de (vi)ver o mundo a partir da nossa percepção com todos os sentidos e pelos olhos dos outros.

Além das pessoas e dos objetos de afeto registrados em contextos privados, algumas crianças produziram fotos ao ar livre. Essas imagens contam dos lugares por onde transitam, ainda que não seja possível ao leitor afirmar que espaços são esses. 
Naiara criou uma imagem de uma escada rústica com sete degraus (Figura 6).$^{10} \mathrm{Em}$ geral às escadas são atribuídos diversos sentidos, como de movimento, deslocamento, desafio, ascensão, entre outros.

O contraste entre o verde da natureza, o cinza da escada e o azul e branco do corrimão sobressaem nessa imagem, capturam a visão de quem a admira. A escada emoldurada, portanto, deve ser significativa à Naiara: foi cuidadosamente enquadrada e ocupa mais da metade da foto.

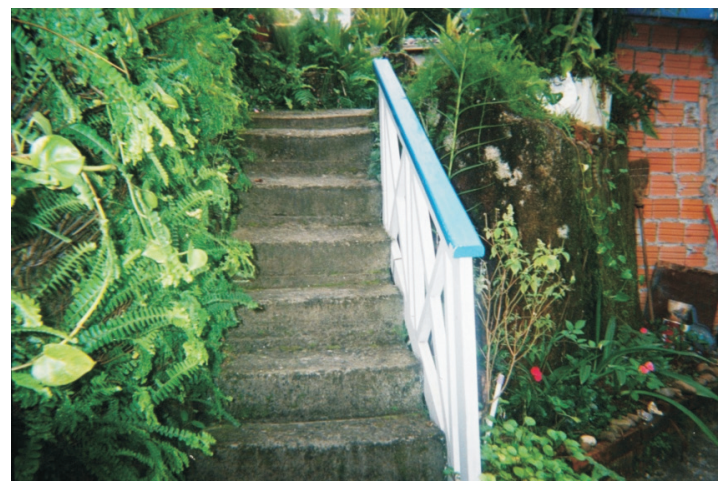

Figura 6 - Escada fotografada por Naiara.

Há uma estética nessa imagem que provoca o leitor a produzir sentidos para o que é dado a ver e, ao mesmo tempo, para o que nesse cenário acontece cotidianamente, mas não está registrado. A bela composição de verde das plantas, cinza, azul e branco da escada, somada à distribuição dessas cores na foto, nos leva a imaginativamente subir ou descer os degraus e conjecturar os locais que conecta, o que há para além do que a foto permite visualizar. Quem por ali transita? As pessoas que nas imediações vivem?

A fotografia de Naiara também, apresentada na Figura $7,{ }^{11}$ expressa sensibilidade, assim como as anteriores. Destacam-se aspectos visuais como o enquadramento, iluminação, ângulo de visão, composição, equilíbrio de cores etc. $\mathrm{O}$ contraste entre os objetos e plantas é marcante.

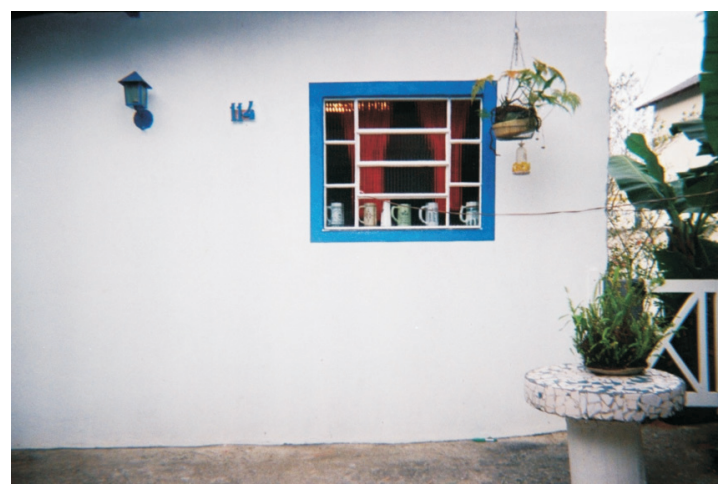

Figura 7 - Casa fotografada por Naiara. 
A riqueza de detalhes da imagem e cada um dos elementos da casa nos levam a compreender tratar-se de um ambiente zelado com muito carinho. Ao analisar a foto podemos imaginar situações de conforto ali vivenciadas.

Sem conversar com as crianças sobre as fotos não há como saber se esta é a casa de Naiara, ou as casas em que Vinícius, Pâmela e Jonathan moram. No entanto, a partir da rede de sentidos que eles constituíram com essa in(ter)venção fotográfica, podemos ler estas imagens e depreender que, independente de habitarem ou não tais espaços, esses contextos as habitam.

\section{Considerações Finais}

As crianças com quem pesquisamos fotografaram o contexto em que vivem a partir de diversos canais perceptivos; diferentes caminhos e meios para a produção, apropriação e objetivação de sentidos. As fotografias produzidas, portanto, revelam a polissemia de seus olhares e refratam olhares outros, possibilitando experiências estéticas aos leitores pautadas pelo ver, ouvir, cheirar, saborear, sentir, imaginar, criar, resistir e (vi)ver.

A produção e a leitura de fotos são sempre mediadas pela experiência, pelas lentes e véus que (in)viabilizam o olhar. Compreendendo estes olhares como socialmente constituídos, tensionamos diferentes modos de (vi)ver o mundo presentes ou ausentes, visíveis ou invisíveis. Analisamos as imagens fotográficas a partir dos fragmentos de olhares nelas expressos; olhares de quem as fotografou e dos pesquisadores que as admiraram.

As fotos deram visibilidade à dimensão afetiva da infância. Foram retratados animais de estimação, espaços do brincar, pessoas, lugares e objetos significativos. Assim, os sentidos enfocados trazem à luz a realidade das crianças, independente de serem crianças com deficiência visual. Este aspecto foi muito significativo: os modos de (vi)ver o mundo expressos nas imagens são antes de tudo olhares de meninas e meninos.

\section{Notas}

1 "Relação estética é uma "relação sensível em que os corpos se afetam e se deixam afetar pela simples possibilidade do encontro. A assunção de relações estéticas, portanto, em vez de estética ou reação estética como se refere Vigotski $(1998 ; 2001)$, demarca a condição inexoravelmente relacional e inventiva da própria condição humana" (ZANELLA, 2013, p. 45).

${ }^{2}$ Todas as famílias consentiram que as crianças participassem mediante assinatura do Termo de Consentimento. Cumpre destacar que o projeto de pesquisa que embasa essa escrita foi aprovado pelo Comitê de Ética em Pesquisa com Seres Humanos da Universidade em que se insere, com o código FR-340245.

${ }^{3}$ Optou-se por utilizar essa grafia do nome do autor, respeitando a grafia original das obras consultadas.

${ }^{4}$ As imagens em que haviam pessoas não serão aqui apresentadas, respeitando a privacidade dos familiares. Apenas as fotos das crianças participantes da oficina, cujo uso da imagem está consentido, serão analisadas.

${ }^{5} \mathrm{Na}$ primeira foto da Figura 1, Ana Carolina sorri diante da câmera abraçando uma boneca, sentada no banco do passageiro de um carro. O seu sorriso é maroto, descontraído e de cumplicidade com a cena; as cores em tons de rosa da sua roupa e da boneca predominam na foto. Na segunda imagem Vinícius com olhos fitos na câmera encontra-se em pé, apoiado em uma mesa de jantar 
na sala de uma casa. Sua jaqueta tem dois tons de azul que contrastam com as cores mais suaves da sala. Ao fundo, uma senhora sentada num sofá observa a cena. Ao centro da terceira foto da Figura 1 Naiara sorri. Num ambiente familiar ela está sentada e ao fundo, sobre um móvel vê-se uma televisão, ao lado uma Bíblia aberta e um vaso com um girassol. No quarto retrato Jonathan faz pose sentado num triciclo motorizado. Seu olhar é dirigido para baixo e os cantos da sua boca estão alegremente erguidos em um doce sorriso. Jonathan é o colorido da imagem; suas roupas azuis contrastam com o plano de fundo árido da foto, formado por um muro com reboque de cimento e um chão também em tom de cinza.

${ }^{6} \mathrm{Na}$ primeira imagem (Figura 2) Pâmela fotografa uma cama de solteiro. Na cabeceira da cama se veem vários bichinhos de pelúcia coloridos dispostos aleatoriamente. Muitos deles estão virados de cabeça para baixo. Na foto à direita (Figura 2) Naiara também fotografa bichinhos de pelúcia e bonecas. Na imagem ela registra um canto de uma sala destinado a brinquedos, um espaço de brincar. Esse canto está localizado na parte esquerda da imagem, à direita ela enquadrou a parede que faz uma quina com esse espaço. Os bichinhos de pelúcia e bonecas estão sob uma pequena mesa coberta por uma toalha colorida, encostados na parede ao fundo. Todos estão dispostos de frente e a maioria sentados na mesinha. Destaca-se um ursinho Puf, maior que os demais, no centro da imagem.

${ }^{7} \mathrm{O}$ cachorro (Figura 3) é de porte grande e seu pelo curto é na maior parte de cor preta. As patas são marrons e no peito ele tem uma mancha branca. Na parte inferior da imagem pode-se ver alguns tijolos e uma grade branca, separando o cachorro e a fotógrafa no instante do click. Na área em que o cachorro se encontra o solo é de terra batida. Ao fundo vemos um muro com reboco de cimento.

${ }^{8} \mathrm{Na}$ fotografia (Figura 4) ela registrou de baixo pra cima, uma gaiola que estava pendurada com um pássaro dentro no teto de um banheiro. As paredes do banheiro são rebocadas com cimento e não estão pintadas. Ao lado esquerdo da gaiola e da imagem vemos um chuveiro. Ao lado direito uma caixa de descarga plástica. $\mathrm{O}$ teto é telha de fibrocimento em tom de cinza e podem-se ver alguns fios de energia elétrica expostos.

${ }^{9}$ Nessa fotografia (Figura 5) ele enquadrou, ligeiramente à direita da imagem, uma televisão 14 polegadas sob uma cadeira de plástico de cor amarela. À esquerda vemos ao chão parte de uma caixa de som na cor preta. Os objetos estão encostados numa parede com reboco de cimento.

${ }^{10}$ Ao centro da Figura 6 vemos a escada, abaixo na lateral à direita vemos um canteiro com capuchinhos, maria-sem-vergonha, espada-de-são-jorge, entre outras plantas. Ao fundo, no canto direito da foto, observamos uma parede sem reboco.

${ }^{11}$ No plano de fundo da Figura 7 vemos uma parede com reboco rústico e pintura branca. $\mathrm{Na}$ parede há uma janela tipo vitrô pintada de azul, com cortinas vermelhas; através dela podem-se ver cinco canecas dispostas cuidadosamente no parapeito. No primeiro plano da imagem vemos um vaso de xaxim com samambaia sobre uma pequena mesa com tampo revestido por cacos de azulejo. Vemos ainda à direita, na parte superior da imagem, outro vaso com uma samambaia, aparentemente suspenso no ar, provavelmente preso ao telhado, um (in)visível da imagem. Preso ao vaso pode-se ver um comedouro para beija-flor. À esquerda observamos uma luminária fixada à parede e uma placa de numeração da casa, ambas pintadas de azul. 


\section{REFERÊNCIAS}

ACHUTTI, L. E. R. Fotoetnografia da Biblioteca Jardim. Porto Alegre: UFRGS/ Tomo, 2004.

ASSIS, N. Jovens, Arte e Cidade: (im)possibilidades de educação estética em programas de contraturno escolar. 2011. Dissertação (Mestrado)-Programa de Pós-graduação em Psicologia da Universidade Federal de Santa Catarina, Florianópolis, 2011.

AXT, M.; KREUTZ, J. R. Sala de aula em rede: de quando a autoria se (des)dobra em in(ter)venção. In: FONSECA, T. M. G.; KIRST, P. G (Org.). Cartografias e devires: a construção do presente. Porto Alegre: UFRGS, 2003. p. 319-339.

BAKHTIN, M. Estética da criação verbal. São Paulo: Martins Fontes, 2003.

BAKHTIN, M. (VOLOCHÍNOV, V. N.). Marxismo e Filosofia da Linguagem. São Paulo: Hucitec, 2010a.

BAKHTIN, M. Problemas da Poética de Dostoiévski. Rio de Janeiro: Forense Universitária, 2010b.

BAVČAR, E. O Ponto Zero da Fotografia. Rio de Janeiro: Very Special Arts do Brasil, 2000.

BAVČAR, E. Celebración de Evgen Bavčar. Diecisiete, [S.1.], v. 1, n. 2, p. 6-43, 2010.

BENJAMIN, W. Reflexões sobre a criança, o brinquedo e a educação. São Paulo: Duas Cidades, 2002.

BROUGÈRE, G. Brinquedo e cultura. São Paulo: Cortez, 1995.

BROUGÈRE, G. A criança e a cultura lúdica. Rev. da Faculdade de Educação, São Paulo, v. 24, n. 2, 1998.

CORD, D.; FERREIRA, E. P. Considerações sobre o discurso visual. In: LENZI, L. H. C. et al. Imagem: intervenção e pesquisa. Florianópolis: UFSC NUP/CED/ UFSC, 2006. p. 39-50.

COSTA, E. A. P.; COIMBRA, C. M. B. Nem criadores, nem criaturas: éramos todos devires na produção de diferentes saberes. Psicologia \& Sociedade, v. 20, n. 1, p. 117-124, 2008. 
DE TACCA, F. Sapateiro: o retrato de casa. 1991. Disponível em: <http://www. studium.iar.unicamp.br/10/4.html>. Acesso em: 27 maio 2010.

DAVID, J.; HAUTEQUESTT, F.; KASTRUP, V. Audiodescrição de filmes: experiência, objetividade e acessibilidade cultural. Fractal: Revista de Psicologia, Niterói, v. 24, n. 1, p. 125-142, jan./abr. 2012.

FARACO, C. A. Linguagem e diálogo: as idéias linguísticas do Círculo de Bakhtin, São Paulo: Parábola, 2009.

FONSECA, T. M. G, et al. Pesquisa e acontecimento: o toque no impensado. Psicologia em Estudo, v. 11, n. 3, p. 655-660, set./dez. 2006.

FREITAS, M. T. A. Nos textos de Bakhtin e Vygotsky: um encontro possível. In: BRAIT, B. (Org.). Bakhtin, dialogismo e construção de sentido. 2. ed. Campinas, SP: UNICAMP, 1997. v. 1, p. 311-330.

JANELA da Alma. Direção: João Jardim e Walter Carvalho. Rio de Janeiro: Copacabana Filmes, 2001. 1 DVD.

JOBIM E SOUZA, S.; CASTRO, L. R. Pesquisando com crianças: subjetividade infantil, dialogismo e gênero discursivo. In: CRUZ, S. H. V. (Org.) A criança fala: a escuta de crianças em pesquisas. São Paulo: Cortez, 2008. p. 52-78.

JUSTO, J. L.; VASCONCELOS, M. S. Pensando a fotografia na pesquisa qualitativa em psicologia. Estudos e Pesquisas em Psicologia, v. 9, n. 3, p. 760774, 2009.

KEMP, L. Sobre fotografia e (in) visibilidades: olhares de crianças com deficiência visual. 2011. Dissertação (Mestrado)-Programa de Pós-graduação em Psicologia da Universidade Federal de Santa Catarina, Florianópolis, 2011.

KOSSOY, B. Os tempos da fotografia: o efêmero e o perpétuo. Cotia, SP: Ateliê, 2007.

KRAMER, S. Autoria e autorização: questões éticas na pesquisa com crianças. Cadernos de Pesquisa, n. 116, p. 41-59, 2002.

MAURENTE, V.; TITTONI, J. Imagens como estratégia metodológica em pesquisa: a fotocomposição e outros caminhos possíveis. Psicologia \& Sociedade, v. 19, n. 3, p. 33-38, 2007.

MORAES, M.; KASTRUP, V. Introdução. In: . Exercícios de ver e não ver: arte e pesquisa COM pessoas com deficiência visual. Rio de Janeiro: NAU editora, 2010. p. XIII-XXIV. 
MUND, R. T. Diferentes olhares: um "tour" com crianças pelo centro histórico da cidade. 2012. Dissertação (Mestrado)-Programa de Pós-Graduação em Psicologia, Universidade Federal de Santa Catarina, 2012.

MÜLLER, F. L. B. A cidade em foco: olhares a partir do bairro Chico Mendes. 2013. Dissertação (Mestrado)-Programa de Pós-graduação em Psicologia da Universidade Federal de Santa Catarina, Florianópolis, 2013.

NEIVA-SILVA, L.; KOLLER, S. H. O uso da fotografia na pesquisa em Psicologia. Estudos de Psicologia, v. 7, n. 2, p. 237-250, 2002.

NUERNBERG, A. H. Contribuições de Vigotski para a educação de pessoas com deficiência visual. Psicologia em Estudo, [S.1.], v. 13, n. 2, p. 307-316, 2008.

OLHOS abertos para ouvir. Direção: Luiza Kemp e Sofia Franco. Florianópolis: Centro de Comunicação e Expressão, 2010. 1 DVD. Disponível em: <http:// vimeo.com/62707556>. Acesso em: 18 de maio de 2012.

PEIXOTO, N. B. O olhar do estrangeiro. In: NOVAES, A.O. (Ed.) O Olhar. São Paulo: Companhia das Letras, 1990. p. 361-366.

SACKS, O. Ver e não ver. In: Companhia das Letras, 1995. p. 123-164. Um antropólogo em Marte. São Paulo:

SACKS, O. O olho da mente. Mente \& Cérebro, [S.1.], v. XV, n. 176, p. 33-43, 2007.

SACKS, O. O olhar da mente. São Paulo: Companhia das Letras, 2010.

SCHWEDE, G. O Paraíso das crianças na Cidade dos Príncipes: a polifonia urbana revelada em imagens fotográficas. 2010. Dissertação (Mestrado)Programa de Pós-graduação em psicologia da Universidade Federal de Santa Catarina, Florianópolis, 2010.

SONTAG, S. Sobre fotografia. São Paulo: Companhia das Letras, 2004.

SOUSA, J. B. O que percebemos quando não vemos? Fractal: Revista de Psicologia, Niterói, v. 21, n. 1, p. 179-184, jan./abr. 2009.

TITTONI, J. (Org.). Sobre Psicologia e Fotografia. In: . Psicologia e fotografia: experiências em intervenções fotográficas. Porto Alegre: Dom Quixote, 2009. p. 07-23.

VIGOTSKI, L. S. Obras Escogidas: Fundamentos de defectología. Madrid: Pedagógica, 1997. tomo V. 
VIGOTSKI, L. S. Psicologia da Arte. São Paulo: Martins Fontes, 1998.

VIGOTSKI, L. S. A Construção do Pensamento e da Linguagem. São Paulo: Martins Fontes, 2001.

VIGOTSKI, L. S. Imaginação e criação na infância: ensaio psicológico - livro para professores. São Paulo: Ática, 2009.

ZANELLA, A. V. Sobre olhos, olhares e seu processo de (re)produção. In: LENZI, L. H. C. et.al. Imagem: intervenção e pesquisa. Florianópolis: UFSC NUP/CED/ UFSC, 2006. p. 139-150.

ZANELLA, A. V. Cidades, imagens e existências entretecidas: reflexões com a refração do encontro entre psicologia social, comunicação e arte. In: BERNARDES, J.; MEDRADO, B. (Org.). Psicologia Social e Políticas de Existência: fronteiras e conflitos. Maceió: ABRAPSO, 2009. p. 95-105.

ZANELLA, A. V. Fotografia e pesquisa em psicologia: retratos de alguns desencontros. In: ZANELA, A. V.; TITTONI, J. Imagens no pesquisar: experimentações. Porto Alegre: Dom Quixote, 2011. p. 15-33.

ZANELLA, A. V. Perguntar, registrar, escrever: inquietações metodológicas. Porto Alegre: UFRGS, 2013.

Recebido em: 18 de junho de 2012 Aceito em: 03 de setembro de 2014 